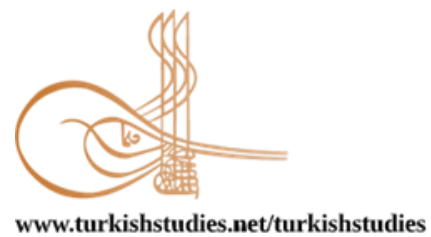

Turkish Studies

\title{
Akademik Personelin COVID-19’a Yönelik Bilgi, Tutum ve Davranışlarının Belirlenmesi
}

\author{
Determination of Knowledge, Attitudes and Behaviors of Academic Staff Towards COVID-19
}

\author{
Sümeyra Ceyhan* - Yasin Uzuntarla**
}

\begin{abstract}
Universities are important centers of education life and academicians play a key role in universities. With this study, it was aimed to determine the level of knowledge, attitude and behavior of academic staff towards COVID-19.This descriptive study was conducted with academic staff working at a state university. Ethics committee approval was obtained from Bingöl University for the research. Online data-based survey method was used as data collection method. In the study, a questionnaire form developed by Srichan et al. (2020) to determine the knowledge, attitude and behavior towards COVID-19 was used. Participation rate in the survey was $49.8 \%$, and the research was completed with 268 academicians. $53.7 \%$ of the participants are male, $41 \%$ are between the ages of $34-43,71.6 \%$ are married, $95.5 \%$ live in the city, $43.3 \%$ have a monthly income of $9001 \mathrm{TL}$ and above. It was found that $32.8 \%$ were lecturers, $49.6 \%$ had a family of 1-3 members. The age range was (25-61) and the mean age was found to be $38.30 \pm 7.69$. It was found that $70.1 \%$ of the participants were worried about infecting their family due to entering collective environments for work, and $24.6 \%$ had death anxiety due to coronavirus. It was found that $83.6 \%$ of the academicians had medium level knowledge, $82.1 \%$ had a high level of attitude and $88.1 \%$ had a high level of behavior. There is a significant positive correlation between knowledge, attitude and behavior towards COVID-19. A significant difference was found in the knowledge level of the participants, the number of members in the family, their attitudes according to their gender and marital status, and their behaviors according to gender, age and status ( $\mathrm{p}<0.05$ ). Academicians' knowledge, attitude and behavior towards COVID-19 are at a sufficient level. It is considered that it would be beneficial to provide academicians with information that will improve their knowledge, attitude and behavior towards COVID-19.
\end{abstract}

Structured Abstract: Introduction: COVID-19 was first seen in people in the seafood and livestock market in Wuhan, China's Hubei Province, in December 2019. With its common name 'Coronavirus', namely '2019nCoV', it was announced as COVID-19 by the World Health Organization (WHO) on February 11, 2020. Steps have been taken to prevent the spread and transmission of the disease in the world and in our country in the processes of public health emergency and epidemic declaration of COVID-19. In this direction, measures such as closing the borders of the country, curfews, quarantine practices, adoption of the principle of working

\footnotetext{
*Öğr. Gör. Dr., Bingöl Üniversitesi, Sağlık Hizmetleri Meslek Yüksek Okulu, Yönetim ve Organizasyon Bölümü Lecturer, PhD., Bingol University, Vocational School of Health Servives, Department of Management and Organization

ORCID 0000-0001-5436-2996

sceyhan@bingol.edu.tr

***Doç. Dr., Gülhane Eğitim ve Araştırma Hastanesi, Sağlık Yönetimi

Associate Professor (PhD), Department of Health Management, Gülhane Training and Research Hospital

ORCID 0000-0002-5021-3763

yasinuzuntarla@gmail.com

Cite as/ Atıf: Ceyhan, S. \& Uzuntarla, Y. (2020). Akademik personelin COVID-19'a yönelik bilgi, tutum ve davranışlarının belirlenmesi. Turkish Studies, 15(6), 259-276. https://dx.doi.org/10.7827/TurkishStudies.45988

Received/Geliş: 27 August/Ağustos 2020

Accepted/Kabul: 15 October/Ekim 2020

Checked by plagiarism software

Copyright (C) MDE, Turkey

Published/Yayın: 20 October/Ekim 2020

CC BY-NC 4.0
} 
from home or flexible / rotational of all employees, especially white-collar workers, starting to use the online education model by interrupting education, in human life and organizations It has paved the way for significant changes in its operation (Akca and Tepe Küçükoğlu, 2020). COVID-19, which affected the whole world, affected the education sector the most after the health sector. In this context, it has been announced that 770 million people worldwide are affected by the pause in education (Zhong, 2020). As a result of the measures taken, education was suspended in almost all countries and each country tried to determine its own method for continuing education. In our country, educational activities, which were suspended due to the epidemic as a result of the press release of the Council of Higher Education dated March 18, 2020, continued with the distance education method (Altuntaş Yılmaz, 2020). Considering the course of the disease in our country as well as the world, the rapidly spreading COVID-19 epidemic is a part of the society at risk and a situation where various occupational groups are at risk. Especially today, many professions require face-toface and close communication with people. People working in such professions with intense human relations are exposed to the threat of the disease. In the process that affects universities and academic staff, this study aimed to determine the level of knowledge, attitude and behavior of academic staff towards COVID-19. In this context, the findings obtained will also benefit multidisciplinary studies in combating epidemics.

Methods: This descriptive study was carried out with academic staff working at a state university between May and June 2020. In the study, it was aimed to reach all of the employees $(\mathrm{N}=538)$ by not calculating the sample. Within the scope of coronavirus measures, employees were reached through online data-based questionnaires instead of face-to-face interviews. However, some personnel did not participate in the study due to reasons such as leave, illness, and not wanting to fill out the questionnaire. Participation rate in the survey was $49.8 \%$, and the research was completed in line with the Helsinki Declaration ethical principles with 268 academic staff who voluntarily participated in the study.

Results: $53.7 \%$ of the participants are male, $41 \%$ are between the ages of $34-43,71.6 \%$ are married, $95.5 \%$ live in the city, $43.3 \%$ have a monthly income of $9001 \mathrm{TL}$ and above. It was found that $32.8 \%$ were lecturers and $49.6 \%$ had a family of 1-3 people. The age range was (25-61) and the mean age was found to be $38.30 \pm 7.69$. When the knowledge levels of the participants about COVID-19 are examined; It was found that $83.6 \%(n=224)$ were medium, $10.4 \%(n=28)$ were weak, $6 \%(n=30)$ were high. When the attitude levels are examined; It was found that $82.1 \%(\mathrm{n}=220)$ of them had a high attitude and $17.9 \%(\mathrm{n}=48)$ had a medium level of attitude. When the behavioral levels of the academicians towards COVID-19 were examined, it was found that $88.1 \%(n=236)$ were high, $11.9 \%(n=32)$ were moderate, and no participants were at a weak level. Descriptive information and correlations for the questions in our study are presented in Table 3. Participants' knowledge level mean score (7.05 \pm 1.10$)$ about COVID-19 is medium, the attitude level average score $(44.23 \pm 4.91)$ is high, and the behavior level is $(26.73 \pm 2.10)$. ) was found to be at a high level.

Discussion and Conclusion: It is seen that there is a slight and significant correlation in the same direction between knowledge, attitude and behavior towards COVID-19 ( $\mathrm{p}<0.01$ ). When the questions about COVID-19 are examined according to sociodemographic characteristics; A statistically significant difference was found in the level of knowledge according to the number of members in the family, attitude level according to gender and marital status, and behavior level according to gender, age group and status. As a result, in our study, the knowledge, attitudes and behaviors of academicians working at a state university towards COVID-19 were found at a positive level. In addition, a significant difference was found in the knowledge level of the academicians according to the number of members in the family, their attitudes according to gender and marital status, and their behavior according to gender, age and status. There is a significant positive correlation between knowledge, attitude and behavior towards COVID-19. It is considered that it would be beneficial to provide academicians with information that will improve their knowledge, attitude and behavior towards COVID-19. In addition, similar studies should be applied to university students to examine students' knowledge, attitude and behavior.

Keywords: Coronavirus Outbreak (COVID-19), Knowledge, Attitude, Behavior, Academic Staff

Öz: Üniversiteler eğitim hayatının önemli merkezleri olup, akademisyenler üniversitelerde kilit rol oynamaktadırlar. Bu çalışma ile akademik personelin COVID-19'a yönelik bilgi, tutum ve davranış düzeylerinin belirlenmesi amaçlanmıştır. Tanımlayıcı nitelikteki bu çalışma bir devlet üniversitesinde görev yapmakta olan akademik personelle gerçekleştirilmiştir. Araştırma için Bingöl Üniversitesi'nden etik kurul 
izni alınmıştır. Veri toplama yöntemi olarak online veri tabanlı anket yöntemi kullanılmıştır. Araştırmada, Srichan ve arkadaşları (2020) tarafından COVID-19'a yönelik bilgi, tutum ve davranışı belirleme amaçlı geliştirilen anket formu kullanılmıştır. Ankete katılım oranı \%49,8 olup, 268 akademisyenle araştırma tamamlanmıştır. Katılımcıların \%53,7'sinin erkek, \%41'inin 34-43 yaş aralığında, \%71,6'sının evli, \%95,5'inin ilde yaşadığ1, \%43,3'ünün 9001 TL ve üzerinde aylık gelire sahip olduğu, \%32,8'inin öğretim görevlisi olduğu, \%49,6'sının ailesinin 1-3 kişiden oluştuğu bulunmuştur. Yaş aralığı (25-61) olup, yaş ortalaması 38,30 $\pm 7,69$ bulunmuştur. Katılımcıların \%70,1'inin iş gereği toplu ortamlara girmekten dolayı ailesine hastalığı bulaştırmaktan endişe duyduğu, \%24,6’sının koronavirüsten dolayı ölüm kaygısı yaşadığı tespit edilmiştir. Akademisyenlerin \%83,6'sının orta düzeyde bilgiye, \%82,1'inin yüksek düzeyde tutuma, \%88,1'inin yüksek düzeyde davranışa sahip oldukları bulunmuştur. COVID-19'a yönelik bilgi, tutum ve davranış arasında anlamlı pozitif korelasyon vardır. Katılımcıların bilgi düzeyinde ailedeki birey sayısına, tutumlarında cinsiyete ve medeni duruma, davranışlarında ise cinsiyet, yaşa ve statüye göre anlamlı farklılık bulunmuştur $(\mathrm{p}<0.05)$. Akademisyenlerin COVID-19' a yönelik bilgi, tutum ve davranışları yeterli düzeydedir. Akademisyenlere COVID-19'a yönelik bilgi, tutum ve davranışlarını geliştirecek bilgiler sunulmasının faydalı olacağı değerlendirilmektedir.

Anahtar Kelimeler: Koronavirüs Salgını (COVID-19), Bilgi, Tutum, Davranış, Akademik Personel

\section{Giriș}

Dünya tarihi incelendiğinde insanların çok çeşitli hastalıklarla mücadele ettikleri, toplu ölümler ve salgın hastalıkların toplumlarda oldukça yaygın bir şekilde görüldüğü varsayılmaktadır. Bilhassa kendi tarihimize de bakıldığında salgın hastalıklara rastlamak mümkündür (Özdinç, 2020). Bu salgın felaketinin en sonuncusu 2019'un aralık ayında ilk kez Çin'in Hubei Eyaleti'ne bağlı Wuhan kentindeki deniz ürünleri ve canlı hayvan pazarında bulunan insanlarda görülmüştür. Yaygın ismiyle 'Koronavirüs' yani '2019-nCoV' Dünya Sağlık Örgütü (WHO) tarafından 11 Şubat 2020 tarihinde COVID-19 olarak açıklanmıştır. COVID-19'a sebep olan virüsün de SARS$\mathrm{CoV}$ ve MERS-CoV gibi diğer hayvanlardan insanlara bulaşan zoonotik bir enfeksiyon olduğu düşünülmektedir (TÜBA, 2020).

COVID-19'un kamu sağlığı acil durumu ve salgın olarak ilan edilme süreçlerinde dünyada ve ülkemizde hastalığın yayılım ve bulaşmasını engellemeye yönelik adımlar atılmıştır. Bu doğrultuda ülke sınırlarının kapatılması, sokağa çıkma yasakları, karantina uygulamaları, beyaz yakalılar başta olmak üzere tüm çalışanların evden ya da esnek/dönüşümlü çalışma prensibinin benimsenmesi, eğitime ara verilerek online eğitim modelinin kullanılmaya başlanması gibi önlemler 2020 yılının Mart ayı itibariyle başlamış, insan hayatında ve örgütlerin işleyişinde önemli değişimlerin yaşanmasına zemin hazırlamıştır (Akca ve Tepe Küçükoğlu, 2020). Tüm dünyayı etkisi altına alan COVID-19 sağlık sektöründen sonra en çok eğitim sektörünü de etkilemiştir. Bu bağlamda dünya genelinde 770 milyon kişinin eğitimin duraklamasından etkilendiği açıklanmıştır (Zhong, 2020). Alınan önlemler sonucunda eğitim öğretime hemen hemen tüm ülkelerde ara verilmiş ve her ülke eğitim öğretimin devam etmesinde kendi yöntemini belirlemeye çalışmıştır. Ülkemizde ise Yükseköğretim Kurulu'nun 18 Mart 2020 tarihli basın açıklaması neticesinde, yaşanan salgın hastalık nedeniyle ara verilen eğitim-öğretim faaliyetleri uzaktan eğitim yöntemi ile devam ettirilmiştir (Altuntaş Yılmaz, 2020).

Salgın hastalık dolayısıyla eğitim sektöründe çözüm odaklı stratejilerin geliştirilmesi gerekliliği ön plana çıkmıştır. Dolayısıyla yeni bir dalgalanmanın oluşması durumunda yaşam biçiminde, çalışma koşullarında ve eğitim sektöründe yeni önlemler ve uygulamalar gündeme gelecektir. Eğitim hayatının önemli merkezleri olan üniversiteler ve üniversitelerde kilit rol oynayan akademisyenler küresel salgının ortaya çıkardığı olumsuzluklardan etkilenmiş ve duruma ayak uydurma çabası içerisine girmiş̧lerdir. Dolayısıyla bu yeni yöntem ve uygulamalardan COVID-19'un bireylerin hayatına girmesiyle birlikte akademisyenlerin de tutumlarına, davranışlarına ve geleceğe yönelik beklentilerine etkileri kaçınılmazdır. Bu bağlamda çalışma ile üniversitelerde yer alan akademik personellerin COVID-19 hastalığına karşı bilgi, tutum ve 
davranış biçimlerinin belirlenmesine yönelik değerlendirme amaçlanmaktadır. Literatürdeki çalışmalar incelendiğinde akademik personellerin salgın hastalıklara yönelik bilgi, tutum ve davranışlarını ele alan çalışmalara rastlanmamıştır. Çalışmamızın amacı doğrultusunda literatüre yeni bir çalışma kazandırılacağı düşünülmektedir.

\section{Kavramsal Çerçeve}

Tarih boyunca ortaya çıkan salgınların ilki olmasa da yaşanılan bilgi ve teknoloji çağında "ironik" bir şekilde insanlık, devasa bir durumda dünyayı tehdit eden COVID-19 yani Koronavirüs yaygın ismiyle bir pandemi ile karşı karşıya kalmıştır. Yeni bir salgın hastalık türü olan bu virüs, ilk olarak Aralık 2019'da Hubei eyaletindeki Wuhan şehrinde tespit edilen ciddi akut solunum sendromuna neden olan bir solunum hastalı̆ğıır (Fauci vd., 2020). Dünya Sağlık Örgütü (WHO) tarafından 11 Şubat 2020'de COVID-19 olarak adlandırılan 'Koronavirüs' "Corona"nın "Co"su, "virüs"ün "vi"si, hastalık anlamındaki ingilizce "disease" sözcügünün "d"si ve 2019 yılında ilk kez görülmesi nedeniyle "19" rakamından oluşturularak COVID-19 olarak tanımlanmıştır (Lovelace, 2020). Dünya Sağlık Örgütü'nün resmi web sitesinde; “Coronavirus'ler (CoV), soğuk alginlı̆̆ından Orta Doğu Solunum Sendromu (MERS-CoV) ve Ă̆gr Akut Solunum Sendromu (SARS-CoV) gibi daha ciddi hastalıklara kadar farklı hastalıklara sebep olan büyük bir virüs ailesidir. Dolayısıyla bu yeni virüs, çeşitli virüsleri de içeren bir virüs ailesi olan koronavirüs olup geçici şekilde "2019-nCoV" olarak adlandırılmış ve 12 Şubat 2020 itibariyle COVID-19 olarak güncellenmiştir. Coronavirus'ler zoonotik olup, hayvanlardan bulaşarak insanlarda hastallğa neden olabilmektedir" (WHO, 2020). Hastalı̆̆ın bilinen semptomları yüksek ateş, boğaz ağrıs1, nefes almada güçlük, öksürük, yorgunluk gibi grip benzeri semptomlar ve nefes darlığ 1 şeklinde ortaya çıkmaktadır. Virüsün mutasyona uğraması nedeniyle son zamanlarda yeni bir semptom olarak ortaya atılan koku kaybı ve konuşma bozukluğu gündeme gelmiştir (Mao ve ark., 2020; Zhu vd., 2020). Literatürdeki çalışmalar incelendiğinde genelde virüsün tanımı, yayılma alanı ve korunma yolları ile ilgili bilgileri içermektedir. Hastalık, COVID-19'lu bir kişinin nefesinde bulunan küçük damlacıklardan veya öksürüğünden yayılabilir. Enfekte olmuş bir bireyin yanında nefes alan kimseler, bu damlacıklar aracılığıyla enfekte olabilmektedir. Ayrıca bu damlacikların olduğu yüzeylere dokunduktan sonra gözlerine, burnuna veya ağzına dokunan kişi de COVID-19 hastalığına yakalanabilir. Semptomu göstermeyen bir bireyin COVID-19 yayma olasılığ 1 düşüktür. Ancak hafif belirtiler gösteren birinin öksürmesi yoluyla da COVID-19 yayılabilir (WHO, 2020).

Ağustos 2020 tarihi itibariyle Dünya Sağlık Örgütü kaynaklı verilere göre dünya genelinde tespit edilmiş toplam vaka sayısı 22.767.009, COVID-19 salgınına bağlı ölüm sayısı 794.435'tir (WHO, 2020). Dünya geneliyle birlikte Türkiye'de de koronavirüs salgını halen etkilerini göstermeye devam ederken, pandemi ile ülkemizde ilk vakanın görülmesinden bu yana toplamda vaka sayısı 6.154.157, COVID-19 kaynaklı can kaybı 6.080 ve iyileşenlerin sayıs1 235.569 civarındadır (covid19bilgi.saglik.gov.tr, 21.08.2020). Koronavirüs salgını tüm dünyaya yayılarak vaka ve ölüm sayılarında sürekli artışın görüldügü günlerde her ülke farklı tedbirleri uygulamaya geçirerek virüs ile mücadele etmeye başlamıştır (Fernandes, 2020; Zheng, vd., 2020). Dünya ile birlikte ülkemizde de hastalık seyrine bakıldığında hızla yayılan COVID-19 salgını, risk altındaki toplumun bir parçası ve çeşitli meslek gruplarının risk altında olduğu bir durumdur. Özellikle günümüzde birçok meslek alanı insanlarla yüz yüze ve yakın iletişim kurmayı gerektirmektedir. İnsan ilişkileri yönü yoğun olan bu tür mesleklerde çalışan kişilerde hastalığın tehdidine maruz kalmaktadır.

Kökeni çok eskilere dayanan üniversiteler, farklı uzmanlık alanlarında hem eğitim hem de araştırma yapan, gelişmekte olan ve gelişmiş ekonomik ihtiyaçları karşılayan vasıflı elemanlar yetiştiren kurumlardır. Diğer bir ifadeyle üniversiteler topluma hizmet sunan, bilginin üretildiği, araştırmaların yapıldığı yükseköğrenim ve bilim kurumları olarak kabul edilmektedir (Büken, 2006). Şüphesiz üniversitelerin temel yapı taşları ise akademik personellerdir. Akademik personel, ön lisans ve üstü düzeyde meslek üyesi yetiştirme görevini üstlenmiş kişilerdir (Erdem, 2012). 
Aynı zamanda akademisyenlik de insanlarla yüz yüze iletişim ve etkileşimin yoğun olduğu mesleklerden biridir. Akademisyenlerin gerek öğrencilerle yoğun iletişimleri, gerekse yayın yapma ve çeşitli faaliyetlere katılma konusunda çeşitli görevleri bulunmaktadır. Bu nedenle, akademik personelin etkinliği ve verimliliğini etkileyebilecek her türlü faktörün üzerinde durulması, eğitsel faaliyetlerin sürdürülebilmesi için çok önemlidir.

Bir sağlık krizi olarak tüm dünyada hayatı olumsuz şekilde etkileyen COVID-19 salgını insanların yaşam biçimlerinde ve örgütlerin işleyişinde büyük değişikliklere sebep olmuştur. $\mathrm{Bu}$ bağlamda COVID-19'dan en çok etkilenen sektörlerden eğitim sektöründe üniversiteler de yerini almıştır. Dolayısıyla eğitim sektöründe önemli yeri olan üniversitelerde kritik rol alan akademisyenlerin COVID-19 sürecinde çalışma şekilleri ve bilimsel faaliyetleri açısından etkilenmeleri kaçınılmaz olmuştur. Ayrıca bu sürecin önümüzdeki günlerde de devam edeceği düşünüldüğünde konuya ilişkin farklı bakış açıları geliştirileceği düşünülmektedir. Üniversiteleri ve akademik personelleri de etkileyen süreç içerisinde gerçekleştirilen bu çalışmada akademik personellerin COVID-19'a yönelik bilgi, tutum ve davranış düzeylerinin belirlenmesi amaçlanmıştır. $\mathrm{Bu}$ bağlamda elde edilen bulgular salgınlarla mücadelede multidisipliner çalışmalara da fayda sağlayacaktır.

\section{COVID-19’a Karşı Bilgi, Tutum ve Davranışlara Özgü Literatür İncelemesi}

COVID-19 ile birlikte, gelişmiş ülkeler de dahil olmak üzere tüm dünyayı etkileyen bir pandemiyle karşı karşıya kalınmıştır. Yaşanan bu durum karşısında, insanların bir kısmı içinde bulunulan çağda böyle bir durumun gerçek olabileceğine ihtimal vermezken bir kısmı ise komplo teorilerinin ardına sığınmıştır. Literatürdeki araştırmalar ve bilim insanlarının yayınladığı raporlar incelendiğinde; aslında küreselleşen dünyada daha fazla salgınlarla karşı karşıya kalınacağı ve bu hastalıkların bütün toplumları etkileyeceği, yıllar öncesinden öngörülmüştür. Dolayısıyla salgınların ne zaman, hangi kaynaktan ya da hangi şekilde ortaya çıkacağ tahmin edilememektedir (Budak ve Korkmaz, 2020). Yapılan çalışmalarda belirli bir bulaşıcı hastalık için bilgi, tutum ve davranışlar hastalığın ciddiyetini, yayılım şiddetini ve ölüm oranını etkilediği görülmektedir. Bu bağlamda çalışamnın amacı akademik personellerin COVID-19'a yönelik bilgi, tutum ve davranış düzeylerinin belirlenmesidir. Ancak literatürdeki çalışmalar incelendiğinde akademik personellere uygulanan araştırmalara rastlanılmamıştır.

Srichan ve arkadaşları (2020) tarafindan COVID-19 ile ilgili olarak Tayland toplumunda gerçekleştirilen çalışmada katılımcıların \%73,4'ünün zayıf bilgiye, \% 28,5'inin zayıf tutuma, \% 13,6'sının yüksek davranışa sahip oldukları bulunmuştur. Reuben ve arkadaşları (2020) tarafından Nijerya toplumunda gerçekleştirilen çalışmada, katılımcıların \% 99,5'inin yüksek düzeyde bilgiye sahip olduğu bulunmuştur. Ayrıca katılımcıların \%92,7'sinin sosyal mesafe/kendi kendine izolasyon uyguladığı, \%96,4'ünün kişisel hijyenine önem verdiği ve \%82,3'ünün yüz maskesi kullanarak olumlu davranış gösterdiği bulunmuştur. Vijai ve Joyce (2020) tarafindan Hindistan toplumunda gerçekleştirilen çalışmada, ankete katılanların \% 89,9'unun COVID-19 hakkında yüksek düzeyde bilgiye sahip olduğu ayrıca gazete ve televizyon haberlerinin en yüksek bilgi kaynağı olduğu bulunmuştur. Ayrıca katılımcıların \% 87,7'si el yıkama, \% 76,3'ünün antibakteriyel dezenfektan kullanma, \% 82,6'sının maske takma önlemlerini uyguladığ bulunmuştur.

Zhang ve arkadaşları (2020) tarafindan Çin'deki sağlık çalışanları ile yapılan çalışmada \%89'unun yeterli bilgiye sahip olduğu, \% 90'ının doğru davranış gösterdiği, deneyimli ve yüksek eğitimli olanların daha olumlu düzeyde oldukları belirlenmiştir. Söğüt ve arkadaşlarının (2020) Türkiye'deki ebelik öğrencileriyle, Khasawneh ve arkadaşlarının (2020) Ürdün'deki tıp öğrencileriyle gerçekleştirdikleri çalışmada katılımcıların büyük bir kısmının yeterli bilgiye sahip oldukları bulunmuştur. Yapılan birçok çalışma, sağlık çalışanlarının bulaşıcı hastalıklara yönelik bilgi, tutum ve davranışlarının iyi düzeyde olduğunu göstermektedir (Sayed ve ark., 2011; Wang ve ark., 2020; Kim ve Oh, 2016; Ergün ve ark., 2020). 
Ulusal ve uluslararası çalışmaların daha çok sağlık çalışanlarında ve toplum genelinde uygulandığı görülmektedir. Eğitim, sanayi, turizm vb. alanlardaki çalışmalar ise oldukça kısıtlıdır.

\section{Gereç Yöntem}

Tanımlayıcı nitelikteki bu çalışma Mayıs-Haziran 2020 tarihleri arasında bir devlet üniversitesinde görev yapmakta olan akademik personeller ile gerçekleştirilmiştir. Araştırmada örneklem hesaplaması yapılmayarak personelin tamamına $(\mathrm{N}=538)$ ulaşılması amaçlanmıştır. Koronavirüs önlemleri kapsamında, yüz yüze görüşme tekniği yerine çalışanlara online veri tabanlı anket yöntemi aracılığıyla ulaşılmıştır. Araştırmanın etik kurul onayı Bingöl Üniversitesi Bilimsel Araştırma ve Yayın Etiği Kurulu'ndan alınmıştır (13.05.2020-E.85052020-07 tarih ve sayılı karar uyarınca). Fakat izin, hastalık, anketi doldurmak istememe gibi nedenlerden dolayı bazı personeller çalışmaya katılım sağlamamıştır. Ankete katılım oranı \%49,8 olup, çalışmaya gönüllü olarak katılan 268 akademik personel ile Helsinki Deklarasyonu etik ilkeleri doğrultusunda araştırma tamamlanmıştır.

\subsection{Anket Formu}

Araştırmada, Srichan ve arkadaşları (2020) tarafından COVID-19'a yönelik bilgi, tutum ve davranışı belirleme amaçlı geliştirilen anket formu kullanılmıştır. Orijinal çalışmadaki sorumlu yazar T. Apidechkul ile iletişime geçilerek soru formunun Türkçe'ye çevrilmesi ve kullanımı konusunda izin alınmış ve anket formunun İngilizce versiyonu tarafımıza gönderilmiştir. Anket formu ileri düzeyde İngilizce bilen üç kişi tarafindan İngilizce'den Türkçe'ye çevrilmiştir. Elde edilen anket, biri dil bilimci, diğer ikisi ana dili İngilizce olan toplam üç kişi tarafından tekrar İngilizce'ye çevrilmiştir. Son aşamada, her iki dildeki biçimlerin eşitliği sağlanarak anlamsal farkl11ık engellenmiştir (Beaten ve ark., 2000). Güvenirlik, bir ölçme aracında yer alan bütün maddelerin homojen olup olmadığını gösterir (Fraenkel ve ark., 2012). Bu çalışmada anket formunun iç tutarlığını test etmek için Cronbach Alfa (CA) katsayısı hesaplanmıştır.

Çalışmada kullanılan anket formu 4 bölümden ve 38 sorudan oluşmaktadır. Anket formu ekte sunulmuştur.

\section{Sosyodemografik Özellikler}

Çalışmaya katılan katılımcıların cinsiyeti, yaşı, medeni durumu, yaşam yeri, aylık geliri, statüsü, ailedeki birey sayısı, işi gereği toplu ortama girmekten kaçınma, koronavirüsten dolayı ölüm kaygısı yaşama gibi literatür bilgileri sonucu yazarlar tarafından oluşturulan dokuz sorudan oluşmaktadır.

\section{COVID-19'un önlenmesi ve kontrolüne ilişskin bilgi düzeyi}

Kat1lımcıların COVID-19'a yönelik bilgi düzeylerinin belirlenmesi amaciyla 10 soru yer almaktadır. Soruların 5'i negatif, 5'i pozitif ifade içermektedir. Yanlış cevaplar için "0", doğru cevaplar için " 1 " puan verilerek hesaplanmaktadır. Bu doğrultuda 0-5 puan alanların bilgi düzeyi zayıf, 6-8 puan alanların orta, 9-10 puan alanların ise iyi olarak değerlendirilmektedir (Srichan ve ark., 2020). Bu bölümdeki örnek ifadeler aşağıdaki gibidir:

- COVID-19 yakın temaslı bulaşıcı bir hastalıktır.

- İyi bir kişisel hijyene sahip olmak COVID-19 enfeksiyonunu önleyebilir.

- COVID-19 aşısı bugün için mevcut değildir.

\section{COVID-19'un önlenmesi ve kontrolüne ilişkin tutum düzeyi}

Katılımcıların COVID-19'a yönelik tutumlarının belirlenmesi amacıyla beşli likert tarzındaki 10 soru yer almaktadır. Soruların 5'i negatif tutum, 5'i pozitif tutum ifade içermektedir. "Tamamen katılmıyorum" için 1, "Tamamen katıllyorum" için 5 puan olacak şeklide 
puanlandırılmıştır. 26 puanın altında olanlar zayıf, 26-40 puan arası orta, 41 ve üzeri puan alanlar ise iyi düzeyde tutuma sahip olarak değerlendirilmektedir (Srichan ve ark., 2020). Bu bölümdeki örnek ifadeler aşağıdaki gibidir:

- Evde kalmak, COVID-19'u önlemenin ve kontrol etmenin iyi bir yoludur.

- Ebeveynleri ziyaret etmek yerine, telefon ve video görüşme ile sohbet edilmesi tercih edilmelidir.

- Arkadaşlarınızla veya iş arkadaşlarınızla yakın mesafede buluşmak, konuşmak sorun oluşturmaz.

\section{COVID-19'un önlenmesi ve kontrolüne ilişkin davranış düzeyi}

Katılımcıların COVID-19'a yönelik yanıt verme davranışlarına yönelik 10 soru yer almaktadır. Sorular 3'lü likert tarzında "her zaman" için 3, "bazen" için 2 ve "asla" için 1 puan olacak şekilde puanlandırılmıştır. Soruların 3'ü negatif, 7'si pozitif ifade içermektedir. 16 puanın altında olanların davranış düzeyi zayıf, 16-24 puan arası orta, 25 ve üzeri puan alanlar ise iyi düzeyde yanıt verme davranışına sahip olarak değerlendirilmektedir (Srichan ve ark., 2020). Bu bölümdeki örnek ifadeler aşağıdaki gibidir:

- Yaşlıları ve diğer hassas bireyleri COVID-19 enfeksiyonundan korumak için etkili tedbirleri uygulama sıklı̆̆,

- Maske takma sıklığı,

- Elleri yıkarken sabun kullanma sıklığı.

\section{2. Ístatistiksel Analiz}

Araştırma verilerinin analizi SPSS (Version 21, Chicago IL, USA) istatistik paket programı ile yapılmıştır. Tanımlayıcı analizler için aritmetik ortalama standart sapma ve frekans analizi kullanılmıştır. Verilerin normal dağılım gösterip göstermediği basılık ve çarpıklık değerleri ile belirlenmiştir. Skewness ve Kurtosis değerlerinin \pm 2 aralığında olmasından dolayı normal dağılım gösterdiği görülmüsstür (Pituch ve Stevens, 2012). Verilerin normal dağılmasından dolayı iki bağımsız grubun karşılaştırılmasında Independent Samples T Test, üç ve daha fazla grubun karşılaştırılmasında One Way ANOVA, gruplar arasındaki farklılıkların belirlenmesinde Post Hoc Tukey Test, değişkenler arası ilişkilerin belirlenmesinde Pearson Korelasyon analizi kullanılmıştır. İstatistiksel olarak $\mathrm{p}<0.05$ değeri anlamlı olarak kabul edilmiştir.

\subsection{Etik}

Çalışmanın bilimsel kurallara uygunluğu açısından gerekli şartlar oluşturulmuştur. Bu doğrultuda araştırma için Bingöl Üniversitesi'nden (13/05/2020 tarih ve 92342550/044/E8505 numaralı) etik kurul izni alınmıştır.

\section{Bulgular}

Katılımcıların \%53,7'sinin erkek, \%41'inin 34-43 yaş aralığında, \%71,6'sının evli, \%95,5'inin ilde yaşadığ $, \% 43,3$ 'ünün 9001 TL ve üzerinde aylık gelire sahip olduğu, \%32,8'inin öğretim görevlisi olduğu, \%49,6'sının ailesinin 1-3 kişiden oluştuğu bulunmuştur. Yaş aralığı (2561) olup, yaş ortalaması $38,30 \pm 7,69$ bulunmuştur. Tablo 1'de katılımciların sosyodemografik özellikleri sunulmuştur. 
Tablo 1: Akademik Personelin Sosyodemografik Özellikleri

\begin{tabular}{|c|c|c|}
\hline Değişkenler & n & $\%$ \\
\hline \multicolumn{3}{|l|}{ Cinsiyet } \\
\hline Kadın & 124 & 46,3 \\
\hline Erkek & 144 & 53,7 \\
\hline \multicolumn{3}{|l|}{ Yaş Grubu(Yll) } \\
\hline$\leq 33$ & 94 & 35,1 \\
\hline $34-43$ & 110 & 41,0 \\
\hline $44 \leq$ & 64 & 23,9 \\
\hline \multicolumn{3}{|l|}{ Medeni Durum } \\
\hline Evli & 192 & 71,6 \\
\hline Yalnız & 76 & 28,4 \\
\hline \multicolumn{3}{|l|}{ Yaşadığ Yer } \\
\hline İl & 256 & 95,5 \\
\hline İlçe & 12 & 4,5 \\
\hline Köy & - & - \\
\hline \multicolumn{3}{|l|}{ Aylik Gelir } \\
\hline$\leq 7000 \mathrm{TL}$ & 56 & 20,9 \\
\hline 7001-9000 TL & 96 & 35,8 \\
\hline$\geq 9001 \mathrm{TL}$ & 116 & 43,3 \\
\hline \multicolumn{3}{|l|}{ Statü } \\
\hline Prof. Dr. & 16 & 6,0 \\
\hline Doç. Dr. & 42 & 15,7 \\
\hline Dr. Öğr. Üyesi & 86 & 32,1 \\
\hline Öğretim Görevlisi & 88 & 32,8 \\
\hline Araştırma Görevlisi & 36 & 13,4 \\
\hline \multicolumn{3}{|l|}{ Ailedeki Birey Sayısı } \\
\hline 1-3 birey & 133 & 49,6 \\
\hline 4-6 birey & 131 & 49,0 \\
\hline 7 ve üzeri birey & 4 & 1,4 \\
\hline
\end{tabular}

"İşiniz gereği toplu ortamlara girmenizden dolayı, ailenize hastalığı bulaştırmaktan endişe duyuyor musunuz?" sorusuna katılımcıların \%70,1'inin $(n=188)$ endişe duyduğu, \%18,7'sinin $(\mathrm{n}=50)$ endişe duymadığ $, \% 11,2$ 'sinin $(\mathrm{n}=30)$ kararsız olduğu bulunmuştur (Şekil 1).

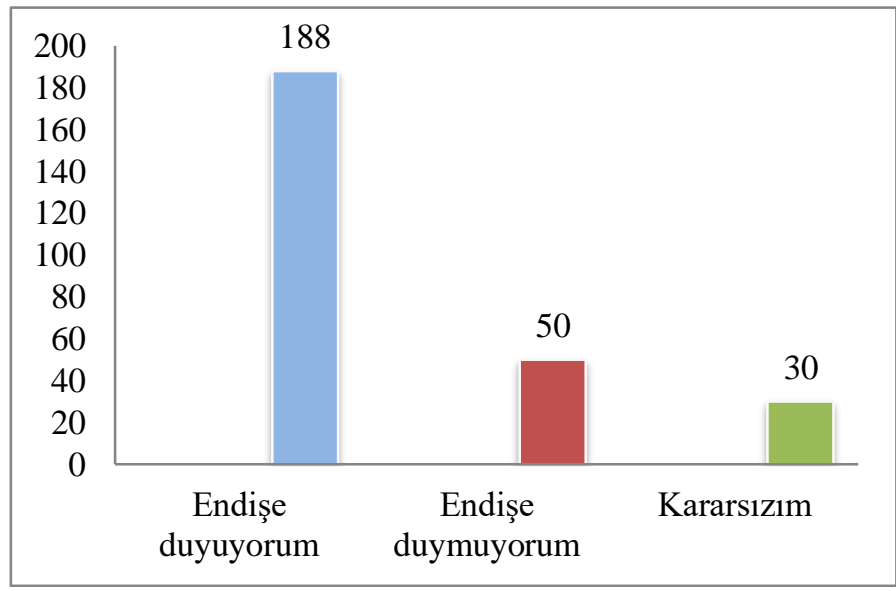

Şekil 1: İş Gereği Toplu Ortamlara Girmekten Dolayı Aileye Hastalığı Bulaştırmaktan Endişe Duymak 
"Koronavirüsten dolayı ölüm kaygısı yaşıyor musunuz?" sorusuna katılımcıların $\% 24,6$ 'sinın $(\mathrm{n}=66)$ evet, \%55,2'sinin $(\mathrm{n}=148)$ hayır, \%20,2'sinin $(\mathrm{n}=54)$ kararsızım yanıtını verdiği bulunmuştur (Şekil 2).

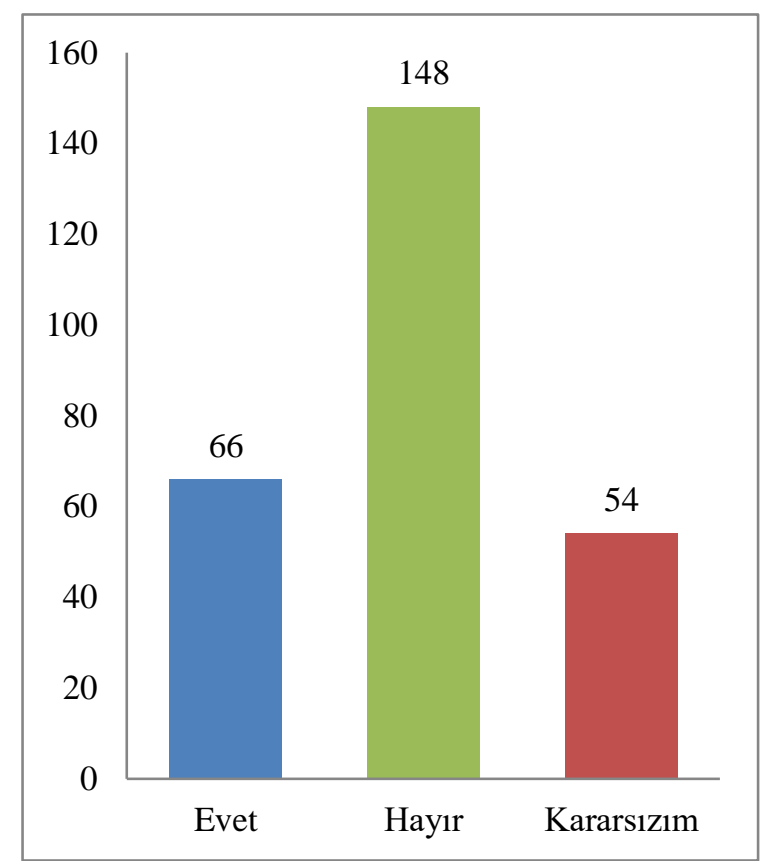

Şekil 2: Koronavirüsten Dolayı Ölüm Kaygısı Yaşama

Kat1lımcıların COVID-19'a yönelik bilgi düzeyleri incelendiğinde; \%83,6'sının (n=224) orta, \%10,4'ünün $(n=28)$ zayıf, $\% 6$ 'sının $(n=30)$ yüksek düzeyde olduğu bulunmuştur. Tutum düzeyleri incelendiğinde; \%82,1'inin $(\mathrm{n}=220)$ yüksek, $\% 17,9$ 'unun $(\mathrm{n}=48)$ orta düzeyde tutuma sahip oldukları bulunmuştur. Akademisyenlerin COVID-19'a yönelik davranış düzeyleri incelendiğinde ise $\% 88,1$ 'inin $(n=236)$ yüksek, \%11,9'unun $(n=32)$ orta düzeyde olduğu, zayıf düzeyde ise hiçbir katılımcının yer almadığı bulunmuş̧ur (Tablo 2).

Tablo 2: Katılımcıların COVID-19'a Yönelik Bilgi, Tutum ve Davranışlarının Dağı̆lımı

\begin{tabular}{|c|c|c|c|c|c|c|}
\hline \multirow[b]{3}{*}{ Bilgi } & \multicolumn{2}{|c|}{ Zayıf } & \multicolumn{2}{|c|}{ Orta } & \multicolumn{2}{|c|}{ Yüksek } \\
\hline & $\mathbf{n}$ & $\%$ & $\mathrm{n}$ & $\%$ & $\mathrm{n}$ & $\%$ \\
\hline & 28 & 10,4 & 224 & 83,6 & 16 & 6,0 \\
\hline Tutum & & & 48 & 17,9 & 220 & 82,1 \\
\hline Davranış & & & 32 & 11,9 & 236 & 88,1 \\
\hline
\end{tabular}

Çalışmamızdaki sorulara yönelik tanımlayıcı bilgiler ve korelasyonlar Tablo 3'de sunulmuştur. Katılımcıların COVID-19'a yönelik bilgi düzeyi puan ortalamasının $(7,05 \pm 1,10)$ orta düzeyde, tutum düzeyi puan ortalamasının $(44,23 \pm 4,91)$ yüksek düzeyde, davranış düzeyinin ise $(26,73 \pm 2,10)$ yüksek düzeyde olduğu bulunmuştur. CA katsayısının 0,7'nin üzerinde olduğu ve güvenilir olduğu görülmektedir (Gürbüz, 2019). COVID-19'a yönelik bilgi, tutum ve davranış arasında aynı yönde, hafif düzeyde ve anlamlı korelasyon olduğu görülmektedir $(\mathrm{p}<0,01)$. 
Tablo 3: Değiş̧kenlerin Korelasyon, Güvenilirlik ve İstatistiki Bulguları

\begin{tabular}{lllllll}
\hline Değişsenler & $\mathbf{1}$ & $\mathbf{2}$ & $\mathbf{3}$ & Ort. & Ss. & CA \\
\hline 1.Bilgi & 1 & & & 7,05 & 1,10 & 0,73 \\
2.Tutum & $0,298^{* *}$ & 1 & & 44,23 & 4,91 & 0,81 \\
3.Davranış & $0,305^{* *}$ & $0,358^{*}$ & 1 & 26,73 & 2,10 & 0,79 \\
\hline
\end{tabular}

$* * \mathrm{p}<0,01$

Sosyodemografik özelliklere göre COVID-19' a yönelik sorular incelendiğinde; ailedeki birey sayısına göre bilgi düzeyinde, cinsiyet ve medeni duruma göre tutum düzeyinde, cinsiyet, yaş grubu ve statüye göre ise davranış düzeyinde istatistiksel olarak anlamlı farklılık bulunmuştur $(\mathrm{p}<0,05)($ Tablo 4).

Tablo 4: Anket Sorularının Sosyodemografik Değişkenlerle İlişkisi

\begin{tabular}{|c|c|c|c|c|c|c|c|c|}
\hline & $\mathrm{n}$ & & Bilgi & & Tutum & & & ivranış \\
\hline & & Ort. \pm Ss. & $\mathbf{p}$ & Ort. \pm Ss. & & $\mathbf{p}$ & Ort. \pm Ss. & $\mathbf{p}$ \\
\hline Cinsiyet & & & & & & & & \\
\hline Kadin & 124 & $7,06 \pm 1,08$ & 0 , & $45,25 \pm 4,19$ & & $\mathbf{0}$ & $27,17 \pm 1,74$ & 0.001 \\
\hline Erkek & 144 & $7,05 \pm 1,13$ & 94 & $43,36 \pm 5,31$ & ,002 & & $26,34 \pm 2,30$ & 0,001 \\
\hline Yaş grubu(yll) & & & & & & & & \\
\hline$\leq 33^{1}$ & 94 & $7,27 \pm 0,92$ & & $45,08 \pm 4,02$ & & & $27,21 \pm 1,73$ & 0,02 \\
\hline $34-43^{2}$ & 110 & $6,94 \pm 1,17$ & 0, & $44,01 \pm 4,79$ & 08 & 0 & $26,50 \pm 2,19$ & $1-2=0,04$ \\
\hline$\geq 44^{3}$ & 64 & $6,93 \pm 1,20$ & 06 & $43,37 \pm 6,06$ & - & & $26,40 \pm 2,32$ & $1-3=0,04$ \\
\hline Medeni durum & & & & & & & & \\
\hline Evli & 192 & $7,01 \pm 1,14$ & 0 , & $43,78 \pm 5,13$ & & $\mathbf{0}$ & $26,65 \pm 2,05$ & 035 \\
\hline Yalnız & 76 & $7,18 \pm 1,00$ & 24 & $45,39 \pm 4,11$ & ,015 & & $26,92 \pm 2,21$ & 0,35 \\
\hline Yaşam yeri & & & & & & & & \\
\hline İl & 256 & $7,06 \pm 1,10$ & & $44,20 \pm 4,97$ & & 0 & $26,69 \pm 2,14$ & \\
\hline İlçe & 12 & $7,00 \pm 1,20$ & 0, & $45,00 \pm 3,41$ & & 0 & $27,50 \pm 0,52$ & 0,19 \\
\hline Köy & - & - & 84 & - & ,58 & & - & \\
\hline Aylık gelir & & & & & & & & \\
\hline$\leq 7000 \mathrm{TL}$ & 56 & $6,96 \pm 0,99$ & & $44,64 \pm 4,40$ & & & $26,96 \pm 2,18$ & \\
\hline 7001-9000 TL & 96 & $7,20 \pm 1,10$ & 0, & $44,18 \pm 5,17$ & & 0 & $26,52 \pm 2,34$ & 0,41 \\
\hline$\geq 9001 \mathrm{TL}$ & 116 & $6,98 \pm 1,15$ & 25 & $44,08 \pm 4,94$ & , 18 & & $26,79 \pm 1,83$ & \\
\hline Statü & & & & & & & & \\
\hline Prof.Dr. ${ }^{1}$ & 16 & $6,87 \pm 1,40$ & & 42,12 & & & $25,62 \pm 3,18$ & \\
\hline Doç.:Dr. ${ }^{2}$ & 42 & $7,04 \pm 1,05$ & & $43,04 \pm 6,09$ & & & $26,71 \pm 1,79$ & \\
\hline Dr.Öğr.Üyesi³ & 86 & $6,95 \pm 1,08$ & & $44,23 \pm 4,81$ & & & 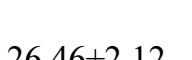 & \\
\hline Öğretim & 88 & & 0,47 & & ,06 & & $20,+0$ & $1-5=0,02$ \\
\hline Görevlisi $^{4}$ & & $1,09 \pm 1,19$ & & $44,63 \pm 4,41$ & & & $26,88 \pm 2,22$ & \\
\hline $\begin{array}{l}\text { Araştırma } \\
\text { Görevlisi }^{5}\end{array}$ & 36 & $7,33 \pm 0,82$ & & $45,61 \pm 3,90$ & & & $27,50 \pm 0,97$ & \\
\hline Ailedeki birey & & & & & & & & \\
\hline saylst & & & & & & & & \\
\hline $1-3^{1}$ & 133 & $7,30=$ & $\mathbf{0 , 0 0 1}$ & 44, & & 0 & 1,76 & 0 \\
\hline $4-6^{2}$ & 131 & 6,84 & $1-2=0,002$ & 44,0 & & 0 & $26,65 \pm 2,41$ & 66 \\
\hline$\geq 7^{3}$ & 4 & $6,01 \pm 0,10$ & $1-3=0,04$ & $47,00 \pm 1,15$ & , 48 & & $27,50 \pm 0,57$ & -66 - 66, \\
\hline
\end{tabular}

Bağımsız Gruplarda T Testi, One Way ANOVA, Post Hoc Tukey TestTartışma ve Sonuç 
Amerika Birleşik Devletleri, Brezilya ve Hindistan dünyada en fazla vakanın görüldüğü ilk üç ülke olup, Türkiye 230 bin vaka ile 17. sıradadır. Ayrıca 185 ülke arasında yaklaşık 6 bin vefat sayısı ile 21. sırada yer almaktadır (WHO, 2020). Salgının ilk görüldüğü günden itibaren Sağlık Bakanlığ 1 bünyesinde Koronavirüs Bilim Kurulu oluşturulmuş ve kurulun tavsiyeleri doğrultusunda Türkiye'de; işyerlerinin ve ibadethanelerin kapatılması, kamuda esnek çalışılması, spor müsabakalarının iptal edilmesi, yurtdışı ve yurtiçi ulaşımın askıya alınması, 18 yaş altı ve 65 yaş üstü bireylerin evlerde karantinaya alınması, askerlerin terhisinin ertelenmesi, 31 ili kapsayan karantina uygulaması gibi sosyal, ekonomik, siyasi, iktisadi, idari, hukuki, askerî, dinî ve kültürel alanlarda birçok önemli etkilere ve sonuçlara neden olan kararlar alınmasına neden olmuş ve zaman zaman bu kararlarda esnekliklere de gidilmiştir. Bu düzenlemelerden eğitim sektörü de etkilenmiş ve okulların kapatılması, eğitimin ve sınavların uzaktan yada online olarak yapılmasına geçilmiştir (TUBA, 2020).

COVID-19'a yönelik yapılan çalışmaların yetersiz olduğu, yayılımını azaltmak amacıyla kontrollerin alınması ve araştırmaların yapılması gerektiği bildirilmektedir (Wu ve ark., 2020). Üniversiteler; inovasyon ve beşeri sermaye gelişiminde kritik bir faktörü temsil etmekte ve bilgi ekonomisinin başarısı ve sürdürülebilirliğinde merkezi bir rol oynamaktadır (Dill ve Van Vught, 2010). Dolayısıyla bilgi üretim merkezi olan üniversitelerde dünyayı derinden etkileyen COVID 19'a yönelik çalışmaların yapılması gerekmekte ve oldukça önem taşımaktadır. Bu çalışma ile bir devlet üniversitesinde görev yapan akademik personelin COVID-19'a yönelik bilgi, tutum ve davranış düzeylerinin belirlenmesi amaçlanmıştır.

Çalışmamızda katılımcıların \%83,6'sının orta düzeyde bilgiye, \%82,1'inin yüksek düzeyde tutuma, \%88,1'inin yüksek düzeyde davranışa sahip oldukları bulunmuştur. Akademisyenlerin COVID-19'a yönelik bilgi, tutum ve davranışlarının iyi düzeyde oldukları değerlendirilmektedir. Çalışmamız; toplum, sağlık çalışanları gibi farklı örneklemlerde yapılan önceki bazı çalışmalarla benzerlik gösterirken (Reuben ve ark., Vijai ve Joyce 2020; Zhang ve ark., 2020); Srichan ve arkadaşlarının (2020) çalışmasına göre oldukça yüksek düzeyde olumlu sonuçlar taşımaktadır. Eğitim seviyesinin yüksek ve sosyo-kültürel yapının gelişmiş olmasının bilgi, tutum ve davranışı artırdığ 1 düşünülmektedir.

Çalışmamızda ailedeki birey sayısı 1-3 olanların, birey sayısı çok olanlara göre daha yüksek düzeyde bilgiye sahip olduğu bulunmuştur. Kadınların erkeklere, yalnızların evlilere göre daha yüksek tutuma sahip olduğu görülmüştür. Ayrıca kadınların erkeklere, genç yaş grubunun orta ve yüksek yaş grubuna, araştırma görevlilerinin profesörlere göre daha olumlu davranışa sahip olduğu bulunmuştur. Bhagavathula ve arkadaşları (2020) tarafından gerçekleştirilen çalışmada mesleğe ve yaşa göre, Kara ve arkadaşları (2020) tarafından gerçekleştirilen çalışmada ise yaşa göre bilgi düzeyinde anlamlı farklılık tespit edilmiştir. Benzer şekilde Bostan ve arkadaşlarının (2020) çalışmasında da kadınların erkeklere göre daha iyi tutum ve davranışa sahip oldukları bulunmuştur. Kadınların erkeklere göre daha yüksek tutum ve davranışa sahip olmasında, kadınların biyopsikososyal özellikleri dolayısıyla hijyene önem verme ve kurallara uyum sağlama yeteneğinin daha yüksek olmasının etkili olduğu düşünülmektedir. Genç yaş grubunun ise aynı zamanda genellikle yalnız ve/veya araştırma görevlisi oldukları, güncel bilgi ve araştırmaları sosyal medya ve internet kullanımı dolayısıyla yakından takip ediyor olmalarının tutum ve davranışlarında daha etkili olduğunu düşündürmektedir.

COVID-19'a yönelik bilgi, tutum ve davranış arasında aynı yönde, hafif düzeyde ve anlamlı korelasyon olduğu bulunmuştur. Bulaşıcı hastalıklarla mücadelede eğitimin önemli rol oynadığı, dolayısıyla COVID-19'a yönelik personelin eğitilmesinin çok önemli olduğu bir gerçektir (Sachan ve ark., 2012; Guanche Garcell, 2020). Uzuntarla (2016) tarafindan gerçekleştirilen bir çalışmada eğitim verilerek bilgi düzeyinin artırılmasının tutum ve davranışı olumlu etkilediği bulunmuş olup, çalışmamızla benzerlik taşımaktadır. 
COVID-19'un aşı ve tedavisinin bulunamamış olması hastalığın nasıl bir seyir izleyeceği konusunda net bir tablo çizilmesini zorlaştırmakta, okullarda eğitimin nasıl verileceği hususunda da tereddütler oluşturmaktadır. Uzaktan eğitime yönelik üniversite öğrencileriyle gerçekleştirilen çalışmalarda; katılımcıların önemli bir kısmının teknik yoksunluk çektiği, \%77'sinin uzaktan eğitimden memnun olmadığı bulunmuştur (Karahan ve ark., 2020; Genç ve Gümrükçüoğlu, 2020). Eğitimin yeni dönemde önce uzaktan, ardından sınıflarda aşamalı ve seyreltilmiş şekilde verilmeye başlanacağı planlanmakta olup, hastalığın okullardaki seyrine göre eğitimdeki yol haritası belirlenecektir.

Çalışmamızda akademisyenlerin \%70,1'inin işi gereği toplu ortamlara girmekten dolayı ailesine hastalığı bulaştırmaktan endişe duyduğu, yaklaşık \%25'inin koronavirüsten dolayı ölüm kaygısı yaşadığ 1 bulunmuştur. Türk toplumunda gerçekleştirilen benzer çalışmalarda katılımcıların durumluk ve sürekli kaygılarının pandemi nedeniyle arttığı bulunmuştur (Çölgeçen ve Çölgeçen,2020; Gökçe ve Kumcağı, 2020) . Öğretmenlerle gerçekleştirilen bir çalışmada katılımcıların \%70'i korku içinde olduklarını ifade etmiştir (Bakioğlu ve Çevik, 2020). Araştırmamız önceki çalışmalarla benzerlik taşımaktadır. Yöneticilerin ve karar alıcıların bu kaygıları göz önünde bulundurarak öğretim kadrosu ve öğrenciler için en sağlıklı koşulları oluşturulması beklenmektedir.

Sonuç olarak çalışmamızda bir devlet üniversitesinde görev yapan akademisyenlerin COVID-19'a yönelik bilgi, tutum ve davranışları olumlu düzeyde bulunmuştur. Ayrıca akademisyenlerin bilgi düzeyinde ailedeki birey sayısına göre, tutumlarında cinsiyete ve medeni duruma göre, davranışlarında ise cinsiyet, yaşa ve statüye göre anlamlı farklılık bulunmuştur. COVID-19'a yönelik bilgi, tutum ve davranış arasında anlamlı pozitif korelasyon vardır. Akademisyenlere COVID-19'a yönelik bilgi, tutum ve davranışlarını geliştirecek bilgiler sunulmasının faydalı olacağı değerlendirilmektedir. Ayrıca üniversite öğrencilerine de benzer çalışmalar uygulanarak öğrencilerin bilgi, tutum ve davranışları incelenmelidir.

Çalışmamızın bazı kısıtlılıkları bulunmaktadır. Araştırma, verilerin toplandığı üniversite ile sınırlıdır ve evrenin tamamına genellenemez. Ayrıca akademisyenlerin davranışlarının değerlendirilmesinde kendi yanıtlarının esas alınması çalışmanın diğer bir sınırlılığıdır.

\section{Kaynakça}

Akça, M., Tepe Küçükoğlu, M. (2020). COVID-19 ve İş Yaşamına Etkileri: Evden Çalışma. Uluslararası Yönetim Eğitim ve Ekonomik Perspektifler Dergisi, 8(1): 71-81.

Altuntaş, Yılmaz, N. (2020). Yükseköğretim Kurumlarında COVID-19 Pandemisi Sürecinde Uygulanan Uzaktan Eğitim Durumu Hakkında Öğrencilerin Tutumlarının Araştırılması: Fizyoterapi ve Rehabilitasyon Bölümü Örneği. Necmettin Erbakan Üniversitesi Sağglk Bilimleri Fakültesi Dergisi, 3(1): 15-20.

Bakioğlu, B. ve Çevik, M. (2020). COVID-19 pandemisi sürecinde fen bilimleri öğretmenlerinin uzaktan eğitime ilişkin görüşleri. Turkish Studies, 15(4): 109-129. https://dx.doi.org/10.7827/TurkishStudies.43502

Beaton, D. E, Bombardier, C., Guillemin, F., Ferraz, M. B. (2000). Guidelines fort the Process of Cross-Cultural Adaptation of Self-Report Measures. Spine, 25: 3186-3191.

Bhagavathula, A. S., Aldhaleei, W. A., Rahmani, J., Mahabadi, M. A., Bandari, D. K. (2020). Knowledge and Perceptions of COVID-19 Among Health Care Workers: Cross-Sectional Study. JMIR Public Health and Surveillance,6(2):e19160. https://dx.doi.org/10.2196/19160 
Bostan, S., Erdem, R., Özturk, Y. E, Kılıç, T., Yılmaz, A. (2020). The Effect of COVID-19 Pandemic on the Turkish Society. Electron J Gen Med, 17(6):em237. https://dx.doi.org/10.29333/ejgm/7944

Budak, F. ve Korkmaz, Ş. (2020). COVID-19 Pandemi Sürecine Yönelik Genel Bir Değerlendirme: Türkiye Örneği, Sosyal Araştırmalar ve Yönetim Dergisi, 1: 62-79.

Büken, N. Ö. (2006). Türkiye Örneğinde Akademik Dünya ve Akademik Etik, Hacettepe Tıp Dergisi, 37: 164-170.

Çölgeçen, Y. ve Çölgeçen, H. (2020). Covid-19 pandemisine bağlı yaşanan kaygı düzeylerinin değerlendirilmesi: Türkiye örneği. Turkish Studies, 15(4): 261-275. https://dx.doi.org/10.7827/TurkishStudies.44399

Dill, D. D., Van Vught, F. A. (eds) (2010). National Innovation and the Academic Research Enterprise; Public Policy in Global Perspective. The Johns Hopkins University Press.

Erdem, A.R. (2012). Bilim İnsanını Yetiştirmede Etik Eğitim, Yükseköğretim ve Bilim Dergisi, $2(1): 25-32$.

Ergün, E., Ergün, Ş., Çelebi, İ. (2020). Acil Sağlık Hizmetleri Personellerinin COVID-19 Hakkında Bilgi, Korunma Düzeyleri ve Etkileyen Etmenler. Paramedik ve Acil Sağllk Hizmetleri Dergisi, 1(1), 16-27.

Fauci, A. S., Lane, H. C., Redfield, R. R. (2020). COVID-19-Navigating the Uncharted. The New England Journal of Medicine, https://dx.doi.org/10.1056/NEJMe2002387

Fernandes, N. (2020). Economic Effects of Coronavirus Outbreak (COVID-19) on the World Economy. Available at SSRN 3557504.

Fraenkel, J.R, Wallen, N.E., Hyun, H.H. (2012). How to Design and Evaluate Research in Education. 8th ed. McGraw-Hill.

Genç, M. F. ve Gümrükçüoğlu, S. (2020). Koronavirüs (Covid-19) sürecinde ilâhiyat fakültesi öğrencilerinin uzaktan eğitime bakışları. Turkish Studies, 15(4): 403-422. https://dx.doi.org/10.7827/TurkishStudies.43798

Göksu, Ö. ve Kumcağız, H. (2020). Covid-19 salgınında bireylerde algılanan stres düzeyi ve kayg1 düzeyleri. Turkish Studies, 15(4): 463-479. https://dx.doi.org/10.7827/TurkishStudies.44397

Guanche Garcell, H. (2020). COVID-19. A Challenge for Healthcare Professionals. Revista Habanera de Ciencias Médicas, 19(2): e_3284_E.

Gürbüz, S. (2019). AMOS ile Yapısal Eşitlik Modellemesi. Seçkin Yayınevi.

Kara, E., Demirkan, K., Unal, S. (2020). Knowledge and Attitudes of Hospital Pharmacist about COVID-19. Turkish Journal of Pharmaceutical Sciences, https://dx.doi.org/ 10.4274/tjps.galenos.2020.72325

Karahan, E., Bozan, M. A., Akçay, A. O. (2020). Sınıf öğretmenliği lisans öğrencilerinin pandemi sürecindeki çevrim içi öğrenme deneyimlerinin incelenmesi. Turkish Studies, 15(4): 201214. https://dx.doi.org/10.7827/TurkishStudies.44348

Khasawneh, A.I., Humeidan, A. A., Alsulaiman, J. W., Bloukh, S., Ramadan, M. (2020). Medical students and COVID-19: Knowledge, attitudes, and precautionary measures. a descriptive study from Jordan. Frontiers in Public Health. https://dx.doi.org/10.3389/fpubh.2020.00253 
Kim, O. S. ve Oh, J. H. (2016). The Convergence Study on Anxiety, Knowledge, Infection Possibility, Preventive Possibility and Preventive Behavior Level of MERS in Nursing Students. Journal of the Korea Convergence Society, 7(3), 59-69.

Lovelace, B. (2020). World Health Organization Names the New Coronavirus: COVID-19. https://www.cnbc.com/

Mao, L., Jin, H., Wang, M., Hu, Y., Chen, S., He, Q., Chang, J.(2020). Neurologic Manifestations of Hospitalized Patients With Coronavirus Disease 2019 in Wuhan, China. JAMA Neurology Journal, 77(6):683-690. https://dx.doi.org/10.1001/jamaneurol.2020.1127

Özdinç, A. (2020). Cumhuriyet'in İlk Yııllarında Frengi: 1916-1925 Yılları Arası Salnamelerde Bolu Sancağı Örneği. Abant Tip Dergisi, 9(1): 8-19.

Pituch, K. A. ve Stevens, J. P. (2012). Applied Multivariate Statistics for The Social Sciences. 4th ed. Routledge.

Reuben, R. C, Danladi, M.M.A., Saleh, D.A. ve Ejembi, P.E. (2020). Knowledge, Attitudes and Practices Towards COVID-19: An Epidemiological Survey in North Central Nigeria. Journal of Community Health, https://dx.doi.org/10.1007/s10900-020-00881-1

Sachan, R., Patel, M. L. Nischal, A. (2012). Assessment of the Knowledge, Attitude and Practices Regarding Biomedical Waste Management Amongst the Medical and Paramedical Staff in Tertiary Health Care Centre. International Journal of Scientific and Research Publications, 2(7): 1-6.

Sayed, M. E., Kue, R., Mcneil, C. ve Dyer, K. S. (2011). A Descriptive Analysis of Occupational Health Exposure in an Emergency Medical Services System. Prehosp Emerg Care, 15: 506510.

Söğüt, S., Dolu, I. ve Cangol, E. (2020). The relationship between COVID-19 Knowledge Levels and Anxiety States of Midwifery Students During the Outbreak: A Cross-Sectional WebBased Survey. Perspectives in Psychiatric Care, https://dx.doi.org/10.1111/ppc. 12555

Srichan, P., Apidechkul, T., Tamornpark, R., Yeemard, F., Khunthason, S. (2020). Knowledge, Attitude and Preparedness to Respond to the 2019 Novel Coronavirus (COVID-19) Among the Bordered Population of Northern Thailand in the Early Period of the Outbreak: A CrossSectional Study. The Lancet, https://dx.doi.org/10.2139/ssrn.3546046

T.C. Sağlık Bakanlığı. (2020). Türkiye Günlük Koronavirüs Tablosu. https://COVID19.saglik.gov.tr/.

Türkiye Bilimler Akademisi (TÜBA). (2020). COVID-19 Pandemi Değerlendirme Raporu. Türkiye Bilimler Akademisi Yayınları, No.34.

Uzuntarla, Y. (2016). Comparison of Young Age Group's Thoughts and Knowledge Levels on Organ Donation in Terms Of Education Given. Turkish J Nephrol, 25: 296-301. https://dx.doi.org/10.5262/tndt.2016.1001.20

Vijai, C. ve Joyce, D. (2020). Novel Coronavirus (COVID-19) Knowledge and Awareness: A Survey of Thiruvallur District, Tamilnadu. Shanlax International Journal of Management, 8(1): 69-76. https://dx.doi.org/10.34293/management.v8i1.322

Wang, C., Hornby, P.W., Hayden, F.G., Gao, G.F. (2020). A Novel Coronavirus Outbreak of Global Health Concern. Lancet, 395(10223): 496.

World Health Organization (WHO). (2020). Coronavirus Disease (COVID-19) Dashboard.: https://COVID19.who.int/table 
World Health Organization (WHO). (2020). Infection Prevention and Control of Epidemic- and Pandemic- Prone Acute Respiratory Infections in Health Care: WHO Guidelines. Geneva: World Health Organization; 2014. p.110.

World Health Organization (WHO). (2020). Who Report: Coronavirus disease 2019 (COVID-19) Situation Report-74. WHO; 2020. p.12.

World Health Organization (WHO). (2020). Coronavirus Disease 2019 (COVID-19) Situation Report -50https://www.who.int/docs/default-source/coronaviruse/situationreports/20200310sitrep-50-COVID-19.pdf?sfvrsn=55e904fb_2

Wu, J.T., Leung, K., Leung, G.M. (2020). Nowcasting and Forecasting the Potential Domestic and International Spread of the 2019-nCoV Outbreak Originating in Wuhan, China: A Modelling Study. Lancet 395: 689-697. https://dx.doi.org/10.1016/S0140-6736(20)30260-9

Zhang, M., Zhou, M., Tang, F., Wang, Y., Nie, H. (2020). Knowledge, Attitude and Practice Regarding COVID-19 Among Health Care Workers in Henan, China. Journal of Hospital Infection, 105:183-187. https://dx.doi.org/10.1016/j.jhin.2020.04.012

Zhang, X. A., Fan, H., Qi, R. Z., Zheng, W., Zheng, K., Gong, J. H., Liu, W. (2020). Importing Coronavirus Disease 2019 (COVID-19) into China After International Air Travel. Travel Medicine and Infectious Disease,35:101620.

Zheng, Y., Goh, E., Wen, J. (2020). The Effects of Misleading Media Reports About COVID-19 on Chinese Tourists' Mental Health: a Perspective Article. Anatolia, 31(2). 337340. https://dx.doi.org/10.1080/13032917.2020.1747208

Zhu, N., Zhang, D., Wang, W., Li, X., Yang, B., Song, J., Niu, P., vd. (2020). A Novel Coronavirus from Patients with Pneumonia in China, 2019. New England Journal of Medicine, 382: 727733. 


\section{EK: COVID-19 İçin Bilgi, Tutum ve Davranışların Belirlenmesine Yönelik Soru Formu}

Bölüm I. Sosyodemografik özellikler

1. Cinsiyetiniz?
a) Erkek
b) Kadin

2. Doğum tarihi

3. Aile gelir düzeyiniz?
a)0-7000 TL
b) $7001-9000 \mathrm{TL}$
c) 9001 ve üzeri TL

4. Ailedeki bireylerin sayısı?
a) $1-3$
b) 4-6
c) 7 ve daha fazla

5. Yaşadığınız yer?
a) $\dot{11}$
b) İlçe
c) Köy

6. Medeni durum?
a) Evli
b) Yalnız

7. Statü
a) Prof.Dr.
b) Doç.Dr.
c) Dr. Öğr.Üyesi
d) Öğr.Görv. e)Arş.Grv.

8. İşiniz gereği toplu ortamlara girmenizden dolayı, ailenize hastalığı bulaştırmaktan endişe duyuyor musunuz?.
a) Endişe duyuyurum
b) Endişe duymuyorum
c) Kararsizim

9. Koronavirüsten dolayı ölüm kaygısı yaşıyor musunuz?
a) Evet
b) Hayır
c) Kararsizım

Bölüm II. COVID-19'un önlenmesi ve kontrolüne ilişkin bilgi düzeyi

\begin{tabular}{|l|l|l|l|}
\hline \multicolumn{1}{|c|}{ No. } & \multicolumn{1}{|c|}{ Soru } & Doğru & Yanlış \\
\hline 1. & COVID-19 yakın temaslı bulaşıcı bir hastalıktır & & \\
\hline 2. $(\mathrm{n})$ & COVID-19'a her gün sağlıksız yiyecekler neden olur & & \\
\hline $3 .(\mathrm{n})$ & COVID-19 tedavi edilebilir bir hastalıktır & & \\
\hline 4. & Herkes COVID-19 enfeksiyonu için savunmasızdır & & \\
\hline 5. & COVID-19 aşısı bugün için mevcut değildir & & \\
\hline $6 .(\mathrm{n})$ & COVID-19 enfeksiyonu için en savunmasız kişiler çocuklardır & & \\
\hline 7. & İyi bir kişisel hijyene sahip olmak COVID-19 enfeksiyonunu önleyebilir. & & \\
\hline $8 .(\mathrm{n})$ & $\begin{array}{l}\text { Sadece COVID-19 ile ilgili belirti ve bulguları olanlar kendini } \\
\text { karantinaya almalıdır. }\end{array}$ & & \\
\hline 9. & Antibiyotik COVID-19 hastalığının tedavisinde kullanılır & \\
\hline $10 .(\mathrm{n})$ & COVID-19 sadece yaşlı nüfusu hedeflemektedir & & \\
\hline
\end{tabular}

* n (negatif soru) 
Bölüm III. COVID-19'un önlenmesi ve kontrolüne yönelik tutumlar

\begin{tabular}{|c|c|c|c|c|c|c|}
\hline No & Soru & $\begin{array}{l}\text { Kesinlikle } \\
\text { katılmıyorum }\end{array}$ & Katılmiyorum & Kararsizım & Katıliyorum & $\begin{array}{l}\text { Kesinlikle } \\
\text { katılıyorum }\end{array}$ \\
\hline 1. & $\begin{array}{l}\text { COVID-19 ciddi bir } \\
\text { hastalıktır }\end{array}$ & & & & & \\
\hline 2. & $\begin{array}{l}\text { COVID-19'u önlemek } \\
\text { ve kontrol etmek için } \\
\text { sağlık merkezindeki bir } \\
\text { doktordan yardım } \\
\text { almalıyı. }\end{array}$ & & & & & \\
\hline 3. (n) & $\begin{array}{l}\text { Sinemaya gitmek için çok } \\
\text { iyi hissediyorum }\end{array}$ & & & & & \\
\hline 4. (n) & $\begin{array}{l}\text { Önümüzdeki birkaç gün } \\
\text { içinde her zamanki gibi } \\
\text { büyükbabamı ve } \\
\text { büyükannemi ziyaret } \\
\text { edeceğim }\end{array}$ & & & & & \\
\hline 5. & $\begin{array}{l}\text { Ebeveynleri ziyaret etmek } \\
\text { yerine, telefon ve video } \\
\text { görüşme ile sohbete } \\
\text { dilmesi tercih edilmelidir. }\end{array}$ & & & & & \\
\hline 6. (n) & $\begin{array}{l}\text { Bayramda dost ve } \\
\text { yakınlarımla toplu } \\
\text { etkinliklere, ziyaretlere } \\
\text { katılacağım. }\end{array}$ & & & & & \\
\hline 7. (n) & $\begin{array}{l}\text { Arkadaşlarınızla veya iş } \\
\text { arkadaşlarınızla yakın } \\
\text { mesafede buluşmak, } \\
\text { konuşmak sorun } \\
\text { oluşturmaz. }\end{array}$ & & & & & \\
\hline 8. & $\begin{array}{l}\text { Evde kalmak, COVID- } \\
19 \text { 'u önlemenin ve kontrol } \\
\text { etmenin iyi bir yoludur. }\end{array}$ & & & & & \\
\hline 9. & $\begin{array}{l}\text { COVID-19'u } \\
\text { önlemek ve kontrol } \\
\text { etmek için sadece } \\
\text { doktorların değil } \\
\text { herkesin } \\
\text { sorumluluğundadır. }\end{array}$ & & & & & \\
\hline 10. (n) & $\begin{array}{l}\text { COVID-19 bilgilerinin } \\
\text { düzenli olarak } \\
\text { güncellenmesi gerekli } \\
\text { değildir. }\end{array}$ & & & & & \\
\hline
\end{tabular}

* n (negatif soru) 
Bölüm IV. COVID-19 önleme ve kontrolüne ilişkin davranış düzeyi

\begin{tabular}{|c|c|c|c|c|}
\hline No. & Soru & Her zaman & Bazen & Hiç \\
\hline 1.(n) & Pazar gibi kalabalık alanlara gitme sıklığı & & & \\
\hline 2.(n) & $\begin{array}{l}\text { İyi tanıdığınız veya tanımadığınız biriyle yakın temas kurma } \\
\text { sıklığı }\end{array}$ & & & \\
\hline 3.(n) & Hastaneye gitme sıklı̆̆ & & & \\
\hline 4. & $\begin{array}{l}\text { COVID-19 hastalığı ile ilgili belirti ve semptomlarla ilgili } \\
\text { kendi kendine kontrol sıklığı }\end{array}$ & & & \\
\hline 5. & $\begin{array}{l}\text { COVID-19'u önlemek ve kontrol etmek için halk sağlı̆ğ } \\
\text { onlemlerine uyum siklığ } 1\end{array}$ & & & \\
\hline 6. & $\begin{array}{l}\text { Yaşlıları ve diğer hassas bireyleri COVID-19 } \\
\text { enfeksiyonundan korumak için etkili tedbirleri uygulama } \\
\text { sıklığı }\end{array}$ & & & \\
\hline 7. & COVID-19 hakkındaki son bilgileri alma sıklığı & & & \\
\hline 8. & Maske takma sıklığ1 & & & \\
\hline 9. & Her gün el yıkama sıklığı & & & \\
\hline 10. & Elleri yıkarken sabun kullanma sıklığı & & & \\
\hline
\end{tabular}

* $\mathrm{n}$ (negatif soru) 